\title{
Cyclic oxidation behaviour of intermetallic Ti-46Al-8Ta alloy in air
}

\author{
T. Pelachová ${ }^{1,2 *}$, J. Lapin ${ }^{1}$ \\ ${ }^{1}$ Institute of Materials and Machine Mechanics, Slovak Academy of Sciences, \\ Račianska 75, 83102 Bratislava 3, Slovak Republic \\ ${ }^{2}$ Faculty of Materials Science and Technology in Trnava, Slovak Technical University, \\ Paulinska 16, 91724 Trnava, Slovak Republic
}

Received 26 August 2015, received in revised form 29 October 2015, accepted 30 October 2015

\begin{abstract}
The cyclic oxidation behaviour of intermetallic Ti-46Al-8Ta (at.\%) alloy was studied in the air. Long-term oxidation experiments were carried out on the samples with convoluted type of $\gamma(\mathrm{TiAl})+\alpha_{2}\left(\mathrm{Ti}_{3} \mathrm{Al}\right)$ microstructure at temperatures ranging from 700 to $800^{\circ} \mathrm{C}$ for oxidation time up to $3100 \mathrm{~h}$. The oxidation kinetics was determined from the weight gain measurements as a function of oxidation time and temperature. The parabolic rate constants and activation energy for oxidation were calculated and discussed. The experimental results showed that the spallation had no significant effect on oxidation kinetic curves at 700 and $760{ }^{\circ} \mathrm{C}$ up to $3100 \mathrm{~h}$ but affected the measured kinetics at $800^{\circ} \mathrm{C}$ for oxidation time longer than $500 \mathrm{~h}$. The EDS and X-ray diffraction observations showed that the scales consisted of $\mathrm{TiO}_{2}, \alpha-\mathrm{Al}_{2} \mathrm{O}_{3}, \mathrm{Ti}_{2} \mathrm{AlN}, \mathrm{TaAlTi}$ and $\mathrm{TiN}$ phases.
\end{abstract}

K e y w o r d s: titanium aluminides, TiAl, cyclic oxidation, microstructure

\section{Introduction}

Titanium aluminides as attractive materials for high-temperature structural applications in automotive, aerospace and power industry have been extensively studied for more than twenty years $[1,2]$. In recent years, different thermo-mechanical treatments and many different alloying additions have been explored to increase room temperature ductility, strength, high-temperature mechanical properties and also to improve high-temperature oxidation resistance of TiAl-based alloys [3-10]. Among various alloying elements, special attention was given to the effect of slow diffusing additions of $\mathrm{Nb}$ and Ta. The additions of $\mathrm{Ta}$ in air-hardenable TiAl-based alloys reduce significantly critical cooling rates needed for transformation of the $\alpha$ phase (Ti-based solid solution with hexagonal crystal structure) to massive $\gamma_{\mathrm{M}}$ [11]. Besides the effect of $\mathrm{Ta}$ on the microstructure refinement, several studies also reported its beneficial effect on high-temperature oxidation properties of some TiAl-based alloys during cyclic oxidation in air at temperatures ranging from 700 to $1000^{\circ} \mathrm{C}[12$ 14]. Ta was found to be more effective in terms of increasing high-temperature oxidation resistance than $\mathrm{Nb}$, particularly at $1000^{\circ} \mathrm{C}$ [14]. Although all studies describe positive effect of $\mathrm{Ta}$ on oxidation resistance of TiAl-based alloys, the experimental results are limited to short oxidation time (up to $380 \mathrm{~h}$ ) and oxidation kinetics lacks clear explanation due to a large fluctuation of experimental results. In addition, since the initial microstructure of intermetallic TiAl-Ta alloys has a significant effect on oxidation behaviour, various microstructure modifications can influence the oxidation kinetics. Hence, new studies on cyclic oxidation behaviour of TiAl-Ta alloys with an optimal microstructure designed for specific industrial applications are of large interest at temperatures corresponding to operating conditions and for long-term oxidation time.

The aim of this article is to study long-term cyclic oxidation behaviour of intermetallic Ti-46Al$-8 \mathrm{Ta}$ (at.\%) alloy with convoluted type of $\gamma(\mathrm{TiAl})$ $+\alpha_{2}\left(\mathrm{Ti}_{3} \mathrm{Al}\right)$ microstructure at temperatures ranging from 700 to $800^{\circ} \mathrm{C}$ in the air up to $3100 \mathrm{~h}$. In addi-

*Corresponding author: tel.: +4212 49268 217; fax: +421 249268 312; e-mail address: ummspela@savba.sk 
tion, the mechanisms and kinetics of the oxidation are reported and discussed.

\section{Experimental procedure}

The Ti-46Al-8Ta (at.\%) alloy was supplied in the form of cast and heat treated cylindrical bars with a diameter of $13 \mathrm{~mm}$ and length of $120 \mathrm{~mm}$. Heat treatments consisted of hot isostatic pressing (HIP) at an applied pressure of $200 \mathrm{MPa}$, the temperature of $1260^{\circ} \mathrm{C}$ for $4 \mathrm{~h}$, which was followed by solution annealing at $1360^{\circ} \mathrm{C}$ for $1 \mathrm{~h}$ and air cooling to room temperature. To obtain the convoluted microstructure, heat treatment was finalized by HIP ageing at an applied pressure of $150 \mathrm{MPa}$, the temperature of $1360^{\circ} \mathrm{C}$ for $2 \mathrm{~h}$ followed by cooling at a rate of $5^{\circ} \mathrm{C} \mathrm{min}^{-1}$. Cylindrical samples with a diameter of $10 \mathrm{~mm}$ and length of $15 \mathrm{~mm}$ for cyclic oxidation tests were cut from heat treated bars (HT). The surface of the samples was lathe machined, polished with $1 \mu \mathrm{m}$ diamond paste and finally washed in acetone and dried. Cyclic oxidation tests were conducted in a resistance furnace at temperatures of 700,760 and $800^{\circ} \mathrm{C}$ and time from $2 \mathrm{~h}$ up to $3100 \mathrm{~h}$ under air. The samples were removed from the furnace at selected time intervals followed by air cooling for $15 \mathrm{~min}$ and then weighed using an analytical balance with an accuracy of $\pm 0.01 \mathrm{mg}$.

The microstructure evaluations of the oxide scales on the surface of the samples were performed by optical microscopy (OM), scanning electron microscopy (SEM), and backscattered scanning electron microscopy (BSEM). Samples for OM and SEM were prepared using standard metallographic techniques and etched in a solution of $150 \mathrm{ml} \mathrm{H}_{2} \mathrm{O}, 25 \mathrm{ml} \mathrm{HNO}_{3}$ and $10 \mathrm{ml} \mathrm{HF}$. The oxidized samples were coated with a thin layer of $\mathrm{Au}$ before SEM examination. Distribution of elements in the scales was measured by energy-dispersive spectrometry (EDS) using JSM-7600F scanning electron microscope. Phase identification of the alloy and oxide scales was carried out by X-ray diffraction analysis (XRD) using Bruker D8 DISCOVER diffractometer equipped with X-ray tube with rotating $\mathrm{Cu}$ anode operating at $12 \mathrm{~kW}$. All measurements were performed in symmetric mode. Diffraction patterns were registered within an angular range $20^{\circ}-100^{\circ}$ of $2 \theta$ with an exposition time of $2 \mathrm{~s}$ and a step size of $0.02^{\circ}$. The volume fraction of coexisting phases was determined from digitalized micrographs using the computer image software SigmaScan Pro.

\section{Results and discussion}

\subsection{Microstructure of alloy}

Figure 1 shows the typical fine grain structure of

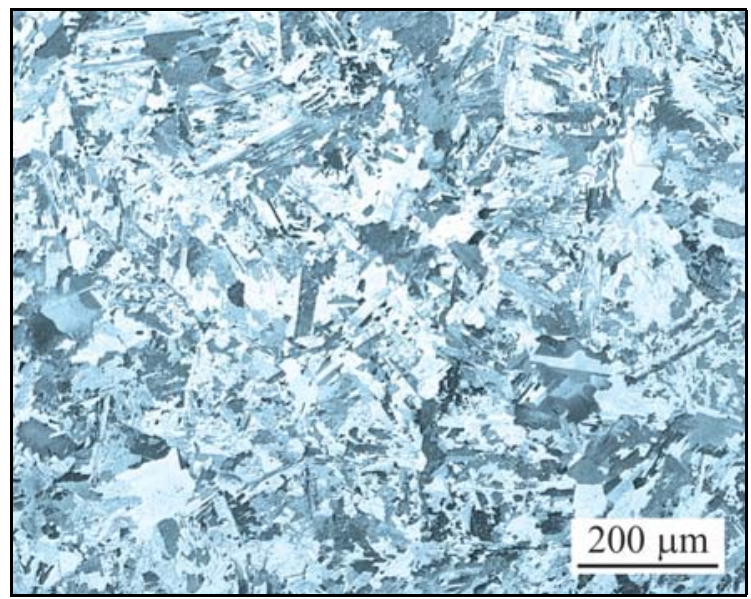

Fig. 1. OM showing fine grain structure of the heat treated Ti-46Al-8Ta (at.\%) alloy.

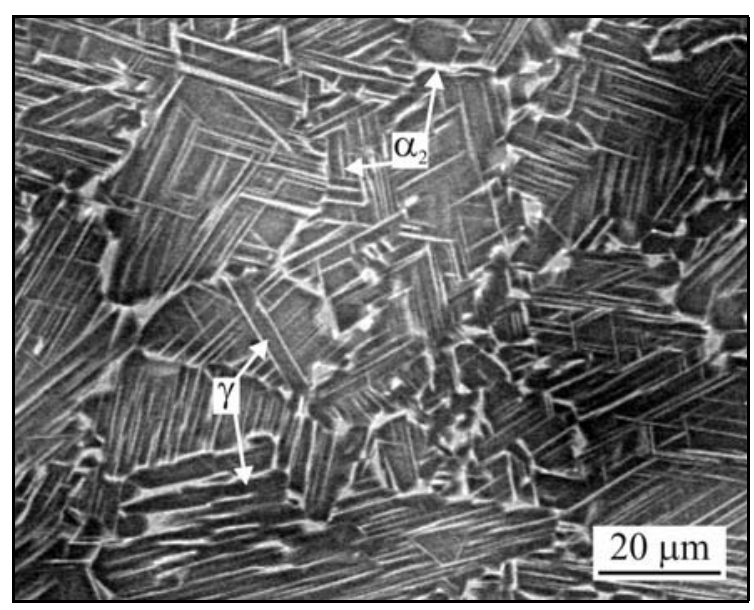

Fig. 2. BSEM micrograph showing the convoluted $\gamma+\alpha_{2}$ type of the microstructure.

the heat treated Ti-46Al-8Ta (at.\%) alloy. The grains are composed of $\gamma(\mathrm{TiAl})$ and $\alpha_{2}\left(\mathrm{Ti}_{3} \mathrm{Al}\right)$ intermetallic phases. Figure 2 shows the convoluted type of $\gamma+\alpha_{2}$ microstructure consisting mostly of plate-like $\alpha_{2}$ phase that forms small colonies within the $\gamma$ phase. As shown by Lapin et al. [15], the $\alpha_{2}$ lamellae and $\gamma$ matrix within the colonies maintain the common Blackburn orientation relationship in the form $\{111\} \gamma \|$ $(0001) \alpha_{2}$ and $[1 \overline{1} 0] \gamma \|[11 \overline{2} 0] \alpha_{2}$. A mean length and average volume fraction of the $\alpha_{2}$ laths are measured to be $8.5 \mu \mathrm{m}$ and $(29.8 \pm 2.3)$ vol. $\%$, respectively. Besides the lamellar colonies, the microstructure of the alloy contains some single-phase $\alpha_{2}$ and $\gamma$ areas predominantly distributed along the grain boundaries.

\subsection{Oxidation kinetics}

Figure 3 shows measured weight gain $\Delta m$ per unit area $A$ of the samples as a function of oxidation time 


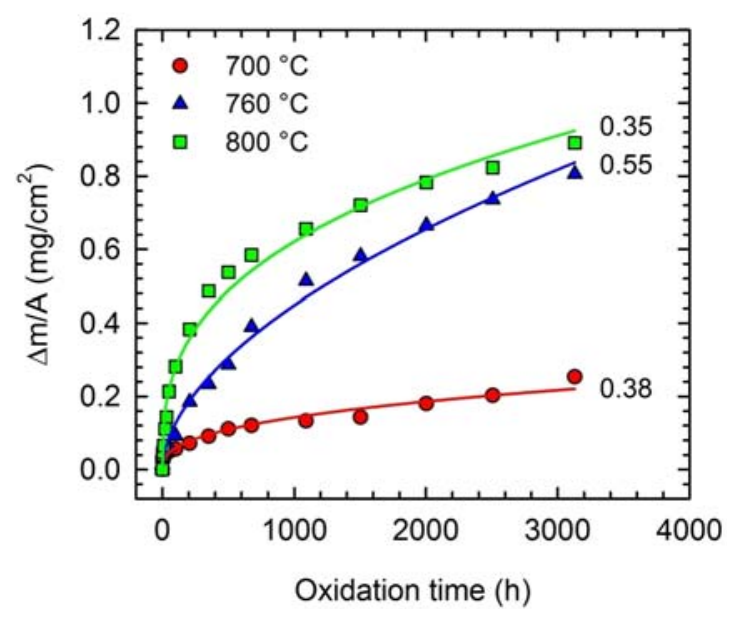

Fig. 3. Dependence of weight gain per unit area on the oxidation time. The studied temperatures are indicated in the figure.

at three studied temperatures of 700,760 and $800^{\circ} \mathrm{C}$. As seen in this figure, the oxidation rate is found to increase with increasing temperature. To analyze the oxidation kinetics, the data was fitted to the power law rate equation:

$$
\frac{\Delta m}{A}=\left(k_{\mathrm{p}} t\right)^{\frac{1}{n}}
$$

where $n$ is the exponent, $k_{\mathrm{p}}$ is the rate constant, and $t$ is the oxidation time. Regression analysis of data shown in Fig. 3 leads to a power law exponent ranging from 0.35 to 0.55 which results in $n$ ranging from 1.82 to 2.85. The correlation coefficients of these fits $r^{2}$ are better than 0.96. As shown by Mitoraj and Godlewska [12] for Ti-46Al-8Ta (at.\%), Luo et al. [16] for Ti-46.5Al-3Ta-2Cr-0.2W (at.\%) and Vojtěch et al. [14] for Ti-44.8Al-6.6Ta (at.\%) alloys, early stages of the oxidation follow the linear kinetic model with a constant of $n=1$ indicating that the forming oxidation scale is not protective. The similar sharp linear increase of the oxidation rate is also observed in the sample oxidized at $800^{\circ} \mathrm{C}$ in the present work up to the oxidation time of about $10 \mathrm{~h}$ (Fig. 3). To investigate whether the oxidation kinetics obeys the parabolic law, the $(\Delta m / A)^{2}$ is plotted as a function of oxidation time in Fig. 4a. It is clear that the parabolic law approximately correlates with measured data at the temperatures of 700 and $760^{\circ} \mathrm{C}$ up to the oxidation time of $3100 \mathrm{~h}$. At the temperature of $800^{\circ} \mathrm{C}$, two regression lines with different slopes indicate a change of the oxidation kinetics of the alloy at the oxidation time of about $500 \mathrm{~h}$. This change in the oxidation kinetics can be attributed mainly to spallation phenomena at $800^{\circ} \mathrm{C}$. It should be noted that only adhered scales of the samples were


Fig. 4. Dependence of $(\Delta m / A)^{2}$ on oxidation time: (a) change of the oxidation kinetics at the temperature of $800^{\circ} \mathrm{C}$ and oxidation time of $500 \mathrm{~h}$; (b) detail showing comparison of the present work with the data published in the work [12] up to the oxidation time of $500 \mathrm{~h}$. The studied temperatures are indicated in the figures.

measured during our experiment. Figure $4 \mathrm{~b}$ shows a comparison of the dependence of $(\Delta m / A)^{2}$ on oxidation time obtained in the present work with the results of Mitoraj and Godlewska [12] for the Ti-46Al-8Ta (at.\%) alloy. The experimentally obtained constants $k_{\mathrm{p}}$ for the studied alloy are summarized in Table 1. Since the experimental data taken from the work [12] are highly dispersed, the parabolic rate constants $k_{\mathrm{p}}$ are only estimated using regression analysis to be $3.136 \times 10^{-14}$ and $1.301 \times 10^{-13} \mathrm{~g}^{2} \mathrm{~cm}^{-4} \mathrm{~s}^{-1}$ at 700 and $800{ }^{\circ} \mathrm{C}$, respectively. While the value of $k_{\mathrm{p}}$ $=1.301 \times 10^{-13} \mathrm{~g}^{2} \mathrm{~cm}^{-4} \mathrm{~s}^{-1}$ is comparable with that of $1.739 \times 10^{-13} \mathrm{~g}^{2} \mathrm{~cm}^{-4} \mathrm{~s}^{-1}$ in the present work at $800^{\circ} \mathrm{C}$, the value of $3.136 \times 10^{-14} \mathrm{~g}^{2} \mathrm{~cm}^{-4} \mathrm{~s}^{-1}$ differs by about one order of magnitude from that in the present work at $700^{\circ} \mathrm{C}$. The high fluctuation of data measured in the work [12] can be explained by a smaller surface of the oxidized samples, microstructural variations, laboratory air used during the exper- 
Table 1. Experimentally obtained parabolic rate constants $k_{\mathrm{p}}$ at the temperatures of 700,760 and $800^{\circ} \mathrm{C}$ for studied alloy

\begin{tabular}{lccc}
\hline \multirow{2}{*}{ Parabolic rate constant } & \multicolumn{3}{c}{ Temperature } \\
\cline { 2 - 4 } & $700^{\circ} \mathrm{C}$ & $760^{\circ} \mathrm{C}$ & $800^{\circ} \mathrm{C}$ \\
\hline$k_{\mathrm{p}}\left(\mathrm{g}^{2} \mathrm{~cm}^{-4} \mathrm{~s}^{-1}\right)$ & $6.854 \times 10^{-15}$ & $4.421 \times 10^{-14}$ & $1.739 \times 10^{-13}$ \\
\hline
\end{tabular}

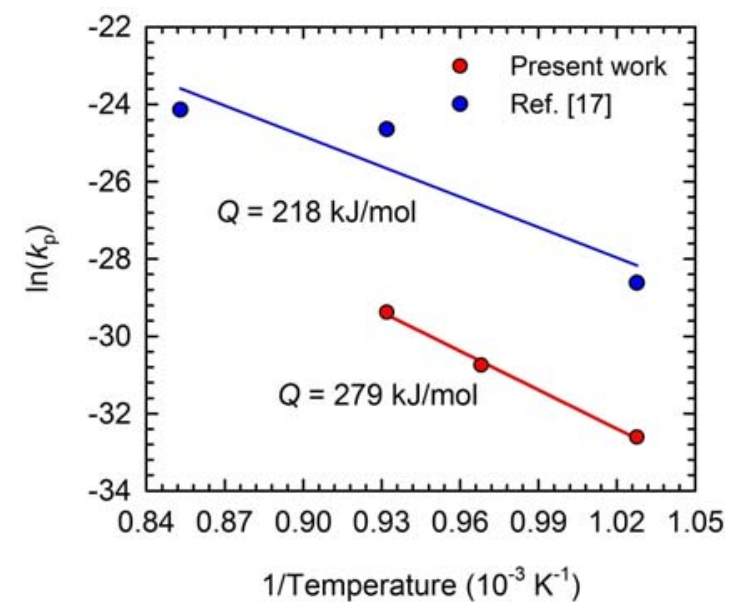

Fig. 5. Arrhenius type of diagram for the parabolic rate constant $k_{\mathrm{p}}$ as a function of inverse temperature.

iment, sample handling during cyclic oxidation experiments and measurements of the weight gain. Vojtěch et al. [14] studied high-temperature cyclic oxidation behaviour of the Ti-44.8Al-6.6 Ta (at.\%) alloy at 800$1000^{\circ} \mathrm{C}$. The regression analysis of the data measured at $800^{\circ} \mathrm{C}$ in the work [14] leads to the values of $k_{\mathrm{p}}=$ $1.294 \times 10^{-13} \mathrm{~g}^{2} \mathrm{~cm}^{-4} \mathrm{~s}^{-1}$ and $k_{\mathrm{p}}=6.953 \times 10^{-13}$ $\mathrm{g}^{2} \mathrm{~cm}^{-4} \mathrm{~s}^{-1}$ for the samples with adhered scales and the samples where spallation was included, respectively. The value of $k_{\mathrm{p}}=1.739 \times 10^{-13} \mathrm{~g}^{2} \mathrm{~cm}^{-4} \mathrm{~s}^{-1}$ measured at $800^{\circ} \mathrm{C}$ in the present work lies between these values and is comparable with the value of $k_{\mathrm{p}}$ $=1.294 \times 10^{-13} \mathrm{~g}^{2} \mathrm{~cm}^{-4} \mathrm{~s}^{-1}$ for the sample with adhered scales in the work [14]. It should be emphasized that the initial microstructure of Ti-44.8Al-6.6 Ta (at.\%) alloy [14] composed of $\gamma+\alpha_{2}$ lamellar grains and the grains with massive $\gamma_{\mathrm{M}}$ phase was significantly different from the convoluted type of microstructure of the studied Ti-46Al-8Ta (at.\%) alloy.

The parabolic law indicates that the oxidation kinetics of the studied alloy is controlled by diffusion in the studied temperature range from 700 to $800^{\circ} \mathrm{C}$ up to the oxidation time of $500 \mathrm{~h}$. Assuming temperature dependence of the parabolic rate constant $k_{\mathrm{p}}$ in the form of Arrhenius type equation, Eq. (1) can be rewritten as follows:

$$
\left(\frac{\Delta m}{A}\right)^{2}=k_{0} \exp \left(-\frac{Q}{R T}\right) t
$$

where $k_{0}$ is a constant, $Q$ is the activation energy for oxidation, $R$ is the universal gas constant, and $T$ is the temperature. Figure 5 shows Arrhenius type of diagram for the parabolic rate constant $k_{\mathrm{p}}$ as a function of inverse temperature. Taking the values of the parabolic rate constants shown in Table 1, one can calculate the activation energy for oxidation of $Q=(279 \pm 6) \mathrm{kJ} \mathrm{mol}^{-1}$. This value is higher than that of $264 \mathrm{~kJ} \mathrm{~mol}^{-1}$ measured for oxidation of Ti-46.5Al-3Ta-2Cr-0.2W (at.\%) alloy by Luo et al. [16] at temperatures between 800 and $900^{\circ} \mathrm{C}$ or value of $218 \mathrm{~kJ} \mathrm{~mol}^{-1}$ reported by Godlewska et al. [17] for Ti-45.9Al-8Nb (at.\%) alloy at temperatures ranging from 700 to $900^{\circ} \mathrm{C}$. However, the measured value of $279 \mathrm{~kJ} \mathrm{~mol}^{-1}$ is lower than the values of 404 and $295 \mathrm{~kJ} \mathrm{~mol}^{-1}$ measured for the activation energy for oxidation of binary $\mathrm{TiAl}$ and $\mathrm{Ti}_{3} \mathrm{Al}$, respectively, at temperatures ranging between 750 and $1000^{\circ} \mathrm{C}$. For the activation energy for self-diffusion of $\mathrm{Ti}$ and $\mathrm{O}$ in $\mathrm{TiO}_{2}$, we can refer to the values of 257 and $234 \mathrm{~kJ} \mathrm{~mol}^{-1}$, respectively [18]. For the activation energy for self-diffusion of $\mathrm{Al}$ and $\mathrm{O}$ in $\mathrm{Al}_{2} \mathrm{O}_{3}$, we can refer to the values ranging from 532 to $795 \mathrm{~kJ} \mathrm{~mol}^{-1}$ and from 281 to $482 \mathrm{~kJ} \mathrm{~mol}^{-1}$, respectively, which were reported by Heuer [19]. The measured value of the activation energy for oxidation indicates that the oxidation process in $\mathrm{Ti}-46 \mathrm{Al}-8 \mathrm{Ta}$ (at.\%) alloy is complex and is controlled not only by the diffusion of $\mathrm{Ti}$ and the diffusion of $\mathrm{O}$ through the oxide scale but also by the diffusion of other elements such as $\mathrm{Ta}$, which can suppress $\mathrm{TiO}_{2}$ growth [16].

\subsection{Oxide scale morphology and composition}

Figure 6 shows oxidized surface of the studied alloy with the typical morphology of oxide scales after selected regimes of oxidation. The short-term oxidation emphasizes the morphology of the initial $\gamma+\alpha_{2}$ microstructure up to the temperature of $760^{\circ} \mathrm{C}$ and time of $25 \mathrm{~h}$, as seen in Figs. 6a, 6b, and 6d. The oxidation time longer than $100 \mathrm{~h}$ and the oxidation at the temperature of $800^{\circ} \mathrm{C}$ lead to the wane of the typical $\gamma+$ $\alpha_{2}$ microstructural features, as shown in Figs. 6c and $6 \mathrm{f}-6 \mathrm{l}$. In general, the oxide scales have good adherence to the alloy surface with quite limited spallation at all studied regimes. Figure 6 shows some cracks on the oxidized surfaces that could lead to spallation during the oxidation at $800^{\circ} \mathrm{C}$. 

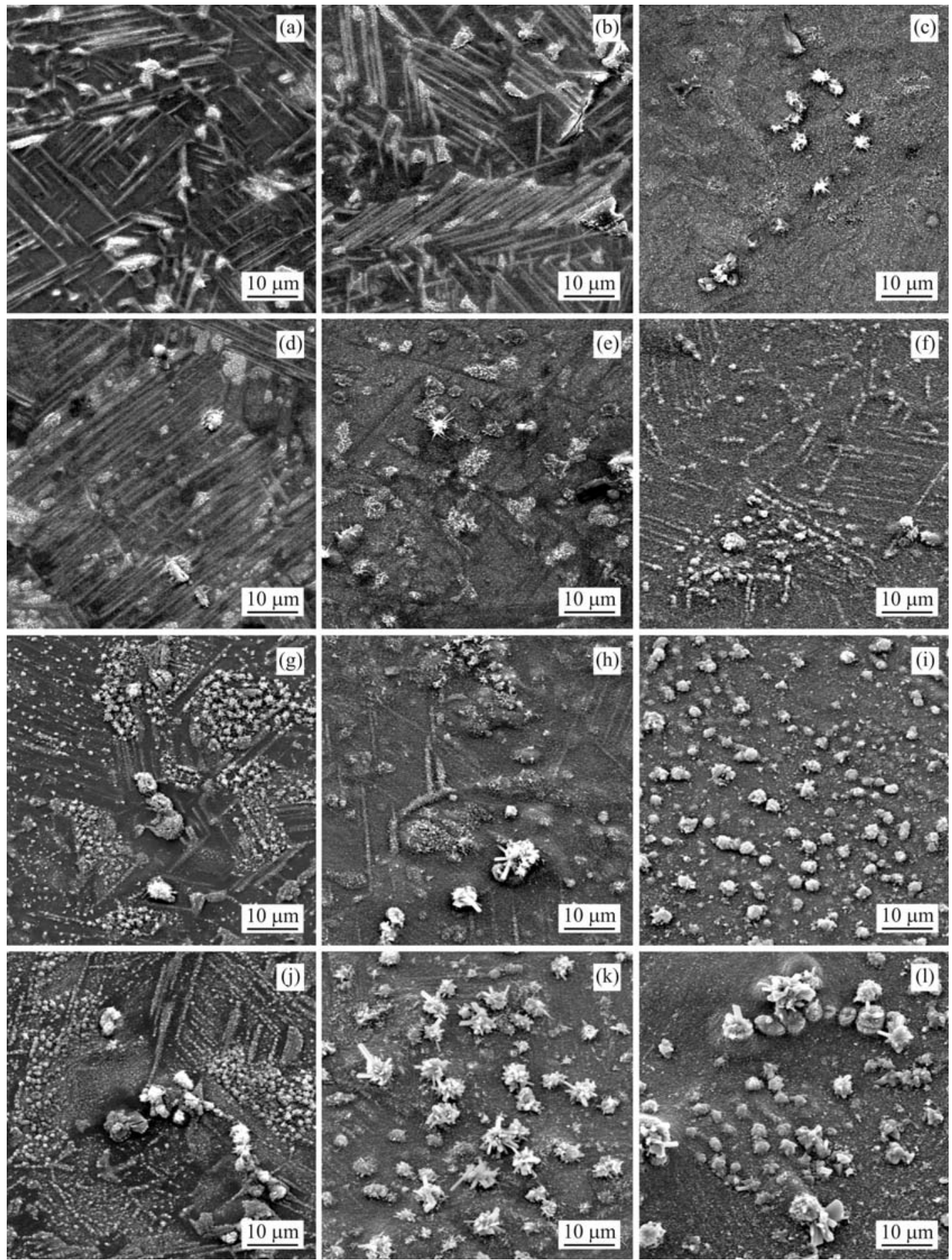

Fig. 6. SEM micrographs showing the surface of the Ti-46Al-8Ta (at.\%) alloy after oxidation at 700,760 and $800{ }^{\circ} \mathrm{C}$ for different oxidation time: (a, b, c) 25 h, (d, e, f) 100 h, (g, h, i) $1000 \mathrm{~h}$ and (j, k, l) $2000 \mathrm{~h}$.

Figure 7 shows phase composition of the alloy surfaces before (HT) and after cyclic oxidation in air using X-ray diffraction. As shown in Fig. 7a, the XRD spectra belong mainly to the basic intermetallic phases of the alloy ( $\mathrm{TiAl}$ and $\mathrm{Ti}_{3} \mathrm{Al}$ ) after oxidation for $25 \mathrm{~h}$. Reflections of $\mathrm{TiO}_{2}$ (rutile) can be clearly visible on XRD spectra after the oxidation for $25 \mathrm{~h}$ at all studied temperatures. The higher temperature, the stronger $\mathrm{TiO}_{2}$ reflections. On the other hand, no clear reflections of $\alpha-\mathrm{Al}_{2} \mathrm{O}_{3}$ (corundum) phase are visible after the oxidation for $25 \mathrm{~h}$. In addition, weak diffraction peaks of TiN phase are also identified. The XRD spectra measured for the time of $100 \mathrm{~h}$ and longer indicate the growth of the oxide scales with the increasing 

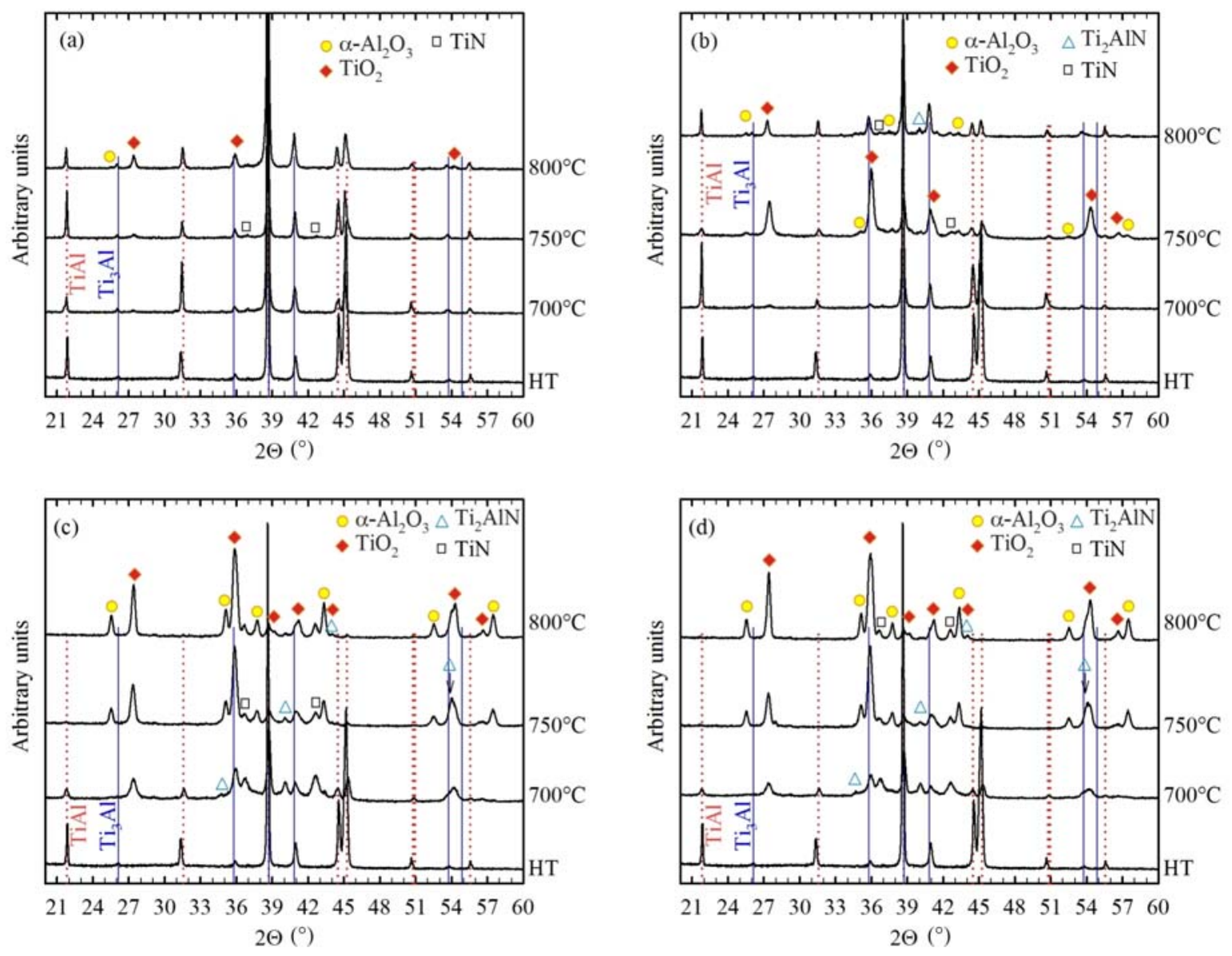

Fig. 7. XRD spectra of the as-received samples (HT) and the samples after oxidation at 700,760 and $800^{\circ} \mathrm{C}$ with duration of (a) $25 \mathrm{~h}$, (b) $100 \mathrm{~h}$, (c) $1000 \mathrm{~h}$ and (d) $2000 \mathrm{~h}$.

temperature and time that results in a decrease of the diffraction intensity of the $\mathrm{TiAl}$ and $\mathrm{Ti}_{3} \mathrm{Al}$ phases, as shown in Figs. 7b, 7c and 7d. At the temperatures of 760 and $800^{\circ} \mathrm{C}$, the $\mathrm{Al}_{2} \mathrm{O}_{3}$ and $\mathrm{TiO}_{2}$ phases are identified as the typical oxidation products. The diffraction maxima of other phases, such as $\mathrm{Ti}_{2} \mathrm{AlN}$ and $\mathrm{TiN}$ are also present on the scale. The same oxidation products were reported in the work [12] after $300 \mathrm{~h}$ oxidation at the temperatures of 700 and $800^{\circ} \mathrm{C}$. The XRD spectra after the oxidation for 1000 and $2000 \mathrm{~h}$ provide clear diffraction maxima shown in Figs. 7c and $7 \mathrm{~d}$. The phase analysis showed the same phase composition of the oxide scales as was formed at the shorter time of oxidation.

Figure 8 shows the distribution of elements and elemental line profiles across the scale and sub-scale zone measured by EDS for the sample oxidized at $800{ }^{\circ} \mathrm{C}$ for $1000 \mathrm{~h}$. SEM micrograph clearly indicates several phases in the scale, as shown in Fig. 8a. Figures $8 \mathrm{~b}$ and $8 \mathrm{c}$ indicate that $\mathrm{Al}-\mathrm{O}$ oxide, which is identified to belong to $\mathrm{Al}_{2} \mathrm{O}_{3}$ is formed in the continuous outer part of the scale and at the interface between the alloy and the scale. The central part of the scale contains Ti-O type of oxide (Fig. 8d) which belongs to $\mathrm{TiO}_{2}$. The central $\mathrm{TiO}_{2}$ layer is decorated by numerous Ta-rich particles, as seen in Fig. 8e. Mitoraj and Godlewska [12] found the same Ta-rich particles in this alloy after cyclic oxidation in air for $300 \mathrm{~h}$ at $800^{\circ} \mathrm{C}$ and described them as TaAlTi phase. Figure 8f shows the concentration profiles along the line 1 in Fig. 8a. The high concentration of $\mathrm{Ti}$ with missing oxygen next to Ta-rich particle could be the TiN phase that was detected by XRD. Comparing the EDS profiles with XRD spectra it can be concluded that the major components of the consecutive layers, starting from the alloy surface are: the mixed scale of $\mathrm{Al}_{2} \mathrm{O}_{3}$ and TaAlTi particles, TiN, $\mathrm{TiO}_{2}$, and $\mathrm{Al}_{2} \mathrm{O}_{3}$. It should be noted that the composition of the scales after $1000 \mathrm{~h}$ cyclic oxidation at $800^{\circ} \mathrm{C}$ is qualitatively the same as that observed after $300 \mathrm{~h}$ oxidation at $800^{\circ} \mathrm{C}$ by Mitoraj and Godlewska [12], which growth obeys the parabolic law.

\section{Conclusions}

The investigation of the long-term cyclic oxidation behaviour of intermetallic Ti-46 $\mathrm{Al}-8 \mathrm{Ta}$ (at.\%) alloy in the air at temperatures of 700,760 and $800^{\circ} \mathrm{C}$ suggests 

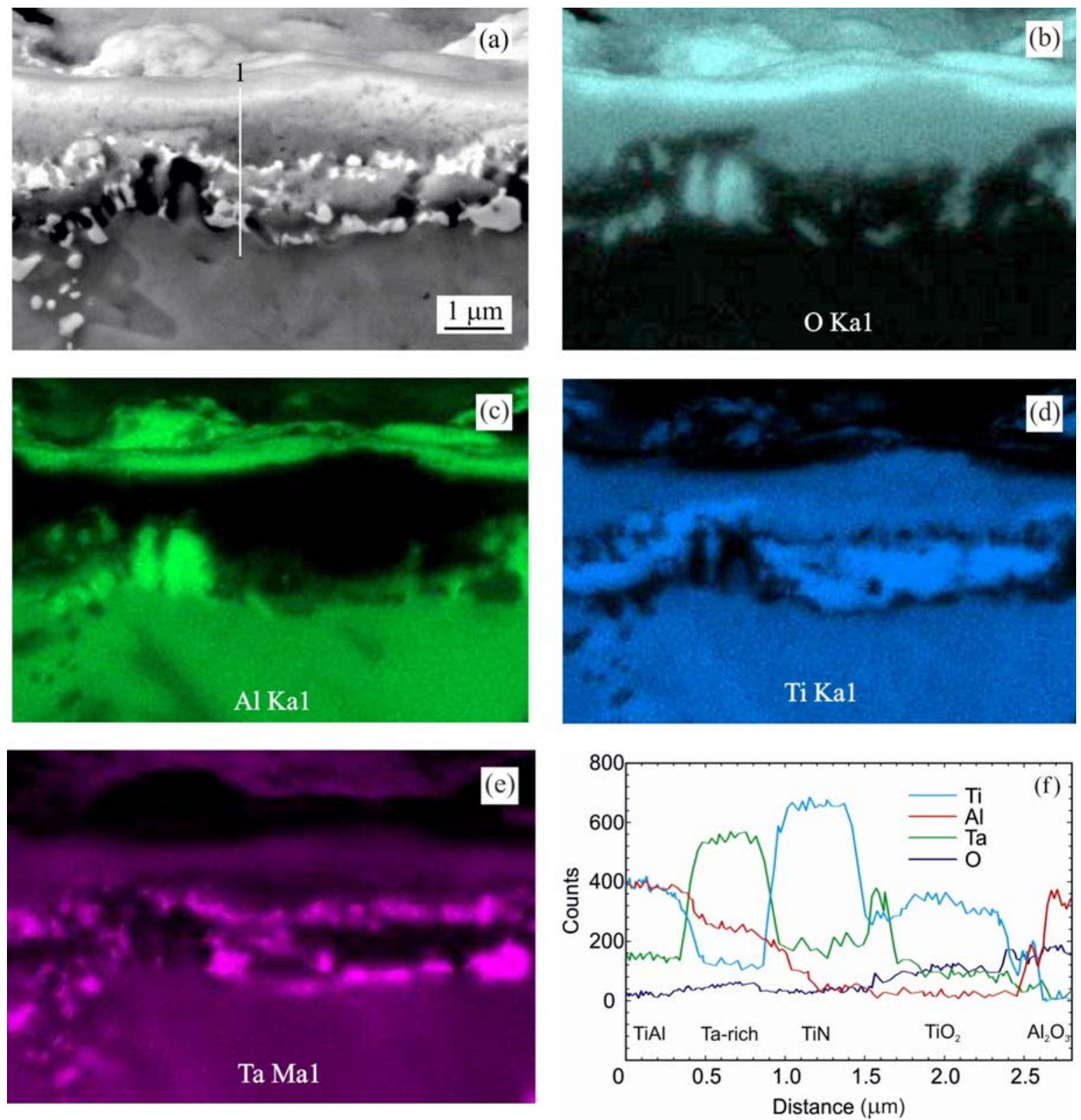

Fig. 8. Cross section of the oxide scale in sample oxidized at $800{ }^{\circ} \mathrm{C}$ for $1000 \mathrm{~h}$ with EDS maps and line profiles: (a) SEM micrograph, (b) distribution of oxygen, (c) distribution of $\mathrm{Al}$, (d) distribution of Ti, (e) distribution of Ta, (f) EDS line profiles of the elements across the oxide scale and sub-scale zone through the line 1 shown in $6 \mathrm{a}$.

the following conclusions:

1. The oxidation kinetics measured by the weight gain per unit area of the samples as a function of oxidation time and temperatures follows the power law with the measured exponent $n$ ranging from 1.82 to 2.85 over the studied temperature range.

2. Assuming the parabolic law for oxidation and experimentally measured parabolic rate constants in the temperature range from 700 to $800^{\circ} \mathrm{C}$ up to the oxidation time of $500 \mathrm{~h}$, the activation energy for oxidation is calculated to be $279 \mathrm{~kJ} \mathrm{~mol}^{-1}$.

3. Starting from the upper surface of the oxidized samples, the major components of the oxide layers are identified by X-ray diffraction and EDS to be $\mathrm{Al}_{2} \mathrm{O}_{3}$ and TaAlTi particles, $\mathrm{TiN}, \mathrm{TiO}_{2}, \mathrm{Ti}_{2} \mathrm{AlN}$, and $\mathrm{Al}_{2} \mathrm{O}_{3}$.

\section{Acknowledgements}

This work is based on the results of the project Competence center for new materials, advanced technologies and energy ITMS 26240220073, supported by the Research and Development Operational Program funded by the European Regional Development Fund and on the results of the project Center for Applied Research of New Materials and Technology Transfer, ITMS 26240220088, 
supported by the Science and Research Operational Program by the European Regional Development Fund.

The authors would like to thank E. Dobročka from the Institute of Electrical Engineering of the Slovak Academy of Sciences for XRD measurements.

\section{References}

[1] Wu, X.: Intermetallics, 14, 2006, p. 1114. doi:10.1016/j.intermet.2005.10.019

[2] Bolz, S., Oehring, M., Lindermann, J., Pyczak, F., Paul, J., Stark, A., Lippmann, T., Schrüfer, S., Roth-Fagaraseanu, D., Schreyer, A., Weiß, S.: Intermetallics, 58, 2015, p. 71 . doi:10.1016/i.intermet.2014.11.008

[3] Zhang, W., Lorentz, U., Appel, F.: Acta Mater., 48, 2000, p. 2803. doi:10.1016/S1359-6454(00)00093-8

[4] Wang, J. N., Xie, K.: Intermetallics, 8, 2000, p. 545. doi:10.1016/S0966-9795(99)00153-3

[5] Novoselova, T., Malinov, S., Sha, W.: Intermetallics, 11, 2003, p. 491. doi:10.1016/S0966-9795(03)00028-1

[6] Liu, B., Liu, Y., Huang, L., Li, H., He, Y.: Mater. Charact., 105, 2015, p. 113. doi:10.1016/j.matchar.2015.05.008

[7] Shu, S., Qiu, F., Tong, C., Shan, X., Jiang, Q.: J. Alloy. Compd., 617, 2014, p. 302. doi:10.1016/j.jallcom.2014.07.199

[8] Beddoes, J., Chen, W. R., Zhao, L.: J. Mater. Sci., 37, 2002, p. 621. doi:10.1023/A:1013786028136
[9] Larson, D. J., Liu, C. T., Miller, M. K.: Mat. Sci. Eng. A, 270, 1999, p. 1. doi:10.1016/S0921-5093(99)00233-6

[10] Cheng, T. T., Willis, M. R., Jones, I. P.: Intermetallics, 7, 1999, p. 89. doi:10.1016/S0966-9795(98)00016-8

[11] Saage, H., Huang, A. J., Hu, D., Loretto, M. H., Wu, X.: Intermetallics, 17, 2009, p. 32. doi:10.1016/j.intermet.2008.09.006

[12] Mitoraj, M., Godlewska, E. M.: Intermetallics, 34, 2013, p. 112. doi:10.1016/j.intermet.2012.10.014

[13] Godlewska, E., Mitoraj, M., Leszczynska, K.: Corros. Sci., 78, 2014, p. 63. doi:10.1016/j.corsci.2013.08.032

[14] Vojtěch, D., Popela, T., Kubásek, J., Maixner, J., Novák, P.: Intermetallics, 19, 2011, p. 493. doi:10.1016/j.intermet.2010.11.025

[15] Lapin, J., Pelachová, T., Dománková, M.: Intermetallics, 19, 2011, p. 814. doi:10.1016/j.intermet.2010.11.023

[16] Luo, Y., Zeng, W., Xi, Z., Mao, X., Yang, Y., Wu, J., Su, H.: Rare Metal Mat. Eng., 44, 2015, p. 282. doi:10.1016/S1875-5372(15)30020-5

[17] Godlewska, E., Mitoraj, M., Devred, F., Nieuwenhuys, B. E.: J. Therm. Anal. Calorim., 88, 2007, p. 225. doi:10.1007/s10973-006-8291-x

[18] Velasco, B. G., Aswath, P. B.: J. Mater. Sci., 33, 1998, p. 2203. doi:10.1023/A:1004395908966

[19] Heuer, A. H.: J. Eur. Ceram. Soc., 28, 2008, p. 1495. $\underline{\text { doi:10.1016/j.jeurceramsoc.2007.12.020 }}$ 